
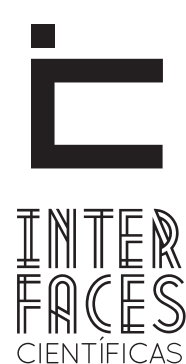

HUMANAS E SOCIAIS

\title{
A JUVENTUDE COMO PROTAGONISTA NO CONSUMO DE PRODUTOS CULTURAIS: 50 ANOS DA JOVEM GUARDA
}

\author{
YOUTH AS A PROTAGONIST IN CONSUMPTION OF CULTURAL PRODUCTS: 50 YEARS OF JOVEM GUARDA \\ LA JUVENTUD COMO PROTAGONISTA EN EL CONSUMO DE PRODUCTOS CULTURALES: 50 AÑOS DE LA JOVEM GUARDA
}

Marcelo Dantas ${ }^{1}$

\section{RESUMO}

O movimento musical Jovem Guarda, que surgiu no Brasil nos anos 1960, marcou profundamente sua época, causando um grande impacto no mercado da música, estendendo sua influência para a TV, o cinema, as revistas, a moda e, principalmente, deflagrando uma verdadeira revolução dos costumes. Esse estudo pretende analisar histórica e sociologicamente esse movimento, inicialmente influenciado pelo pop rock internacional, mas que conseguiu criar sua própria estética, expressando os novos valores urbanos de uma sociedade em acelerado processo de desenvolvimento, modernizando o mercado musical brasileiro. É a primeira vez que o jovem se torna consumidor em massa, distinguindo-se do público "adulto em geral", definindo suas preferências de consumo e transformando para sempre o mercado e os costumes. Hoje, 50 anos depois, a economia distingue o consumidor jovem como estratégico para os negócios e principal indicador das tendências de consumo, não apenas de produtos culturais, mas do mercado como um todo.

\section{PALAVRAS CHAVE}

Juventude. Economia da Cultura. Jovem Guarda. 


\section{ABSTRACT}

The musical movement Jovem Guarda, which emerged in Brazil in the 1960s, deeply marked his time, making a big impact in the music business, extending its influence to the TV, movies, magazines, fashion and, especially, triggering a real revolution of morals. This study aims to analyze historically and sociologically this movement, initially influenced by international pop rock, but managed to create its own aesthetic, expressing the new urban values of a society in rapid development process, modernizing the Brazilian music market. It is the first time the young become mass consumer, distinguishing the public "adult in general," defining their consumer preferences and changing forever the market and customs. Today, 50 years later, the economy distinguishes the young consumer as strategic for business and leading indicator of consumer trends, not only of cultural products but the market as a whole.

\section{KEYWORDS}

Youth. Culture Economy. Jovem Guarda.

\section{RESUMEN}

El movimiento musical Jovem Guarda, que surgió en Brasil en la década de 1960, dejó una profunda huella en su tiempo, teniendo un gran impacto en el negocio de la música, extendiendo su influencia a la televisión, el cine, las revistas, la moda y, sobre todo, originando una verdadera revolución de las costumbres. Este estudio tiene como objetivo evaluar histórica y sociológicamente este movimiento, inicialmente influenciado por el pop rock internacional, pero que logró crear su propia estética, expresando los nuevos valores urbanos de una sociedad en un rápido proceso de desarrollo, modernizando el mercado musical brasileño. Es la primera vez que el joven se convierte en un consumidor masivo, distinguiéndose del público "adulto en general", definiendo sus preferencias de consumo y cambiando para siempre el mercado y las costumbres. Hoy, 50 años después, la economía subraya el consumidor joven como estratégico para los negocios y principal indicador de las tendencias de consumo, no solamente de los productos culturales, sino del mercado en general.

\section{PALABRAS CLAVE}

Juventud. Economía de la Cultura. Jovem Guarda. 


\section{INTRODUÇ̃̃̃}

\subsection{A JUVENTUDE - EVOLUÇ̃̃O DO CONCEITO}

A evolução da juventude como conceito atravessa períodos da história do mundo ocidental e, mais recentemente, no sistema capitalista - que hoje prevalece no mundo inteiro. Inicialmente, as primeiras referências à juventude a posicionam como etapa da vida, faixa etária, circunstância de tempo passageira. Nas sociedades antigas, muito mais que juventude como coletividade de um território, reino, até mais tarde a nação, o que prevalece é a figura do jovem na sua individualidade.

A Grécia, um dos berços da chamada civilização ocidental, traz à tona a valorização do jovem, em razão da beleza e da sexualidade. A sociedade da Grécia antiga - por meio da herança que nos deixou dos seus filósofos, dramaturgos, matemáticos e artistas, principalmente escultores - produziu uma boa parte desse patrimônio a partir da idealização e, por vezes, adoração, da beleza, força e sensualidade da juventude.

Camille Paglia (1992, p. 110-112), na sua obra sobre o sexo e a arte na cultura ocidental da antiguidade ao século XIX, Personas Sexuais, chama a atenção para o menino bonito como o deflagrador da fase da grande arte grega:

A grande arte grega começa no fim do séc VII a.C, com o arcaico kouros (jovem), estátua um pouco maior que o natural de um atleta vitorioso. [...]. O menino bonito, como já observei, é uma das grandes personas sexuais do Ocidente. Como Ártemis, não tem equivalente exato em outras culturas. Seu culto retorna sempre que o apolinismo renasce, como na arte do Renascimento italiano. 0 menino bonito é um andrógino, luminosamente masculino e feminino. Tem estrutura muscular masculina, mas um suave ar de mocinha. [...]. O sorridente kouros é a primeira escultura inteiramente individual na arte. [...]. Não é rei nem deus, mas juventude humana.

Essa valorização da juventude, concentrada no indivíduo, também vai alcançar as mulheres, em socie- dades pré-cristãs, cujos cultos pagãos valorizavam o sacrifício - mais tarde transformado em ritual apenas simbólico - de virgens nos altares à Deusa, ou à Mãe Terra. Essa valorização da virgindade na mulher jovem vai perdurar por meio da expansão do cristianismo no planeta e influenciar todo o mundo ocidental até tempos mais contemporâneos. Finalmente, as mulheres do século XX começam a romper com esse tabu. Já nos anos 1950, marcado pelo crescimento do capitalismo pós Segunda Guerra Mundial, as mulheres começam a conquistar espaço no mundo da educação e do trabatho e isso vai levar a transformações mais diversas.

A partir dos anos 1940, homens e mulheres começam a ser categorizados juntos dentro de um novo conceito de juventude: os americanos passam a usar a expressão teenager para se referir à categoria de jovens entre 13 e 19 anos, (SAVAGE, 2009, p. 11):

Desde o início, foi um termo de marketing usado por publicitários e fabricantes que refletia o poder de consumo recentemente visível dos adolescentes. 0 fato de que, pela primeira vez, os jovens se tornaram um público-alvo também significava que eles tinham se transformado num grupo etário específico com rituais, direitos e exigências próprios.

Esse fenômeno, que começa a ser detectado nos Estados Unidos pós Segunda Guerra, vai se tornar uma realidade mundial a partir dos anos 1950 , quando 0 conceito de juventude começa a se modificar: não mais se referir apenas a uma faixa etária do indivíduo, mas a uma condição social coletiva, diferenciada do mundo das crianças e do mundo dos adultos. A juventude passa a ser um agente social (HOBSBAWM, 1995).

Para essa concepção se firmar no imaginário dos próprios jovens e das sociedades capitalistas ocidentais, será fundamental a popularidade do cinema americano no mercado mundial do período - por meio 
de filmes como Juventude Transviada (Rebel without a Cause, Nicholas Ray, 1955), No Clamor do Sexo (Splendor in the Grass, Elia Kazan, 1961), O Selvagem (The Wild One, Lázló Benedek, 1953), entre outros - e, principalmente a partir do surgimento do rock e seu espetacular sucesso junto à juventude americana e depois do mundo inteiro.

\section{ROCK INGÊNUO DOS ANOS 50 EXPLODE EM SUCESSO NO BRASIL}

Os primeiros ventos de uma música jovem, dançante e ingênua, vão soprar no Brasil ainda no final dos anos 1950. É o período dos ícones rebeldes do cinema e da música americana, como James Dean, Marlon Brando e Elvis Presley. Apesar dessa aura de rebeldia inicial, o sucesso entre os jovens brasileiros vai acontecer apenas com o lado dançante - em ritmo de twist e rock - já que o discurso das canções será da mais inofensiva ingenuidade. Entretanto, os tempos austeros ainda imperam e os jovens brasileiros vão ter que enfrentar a recriminação dos pais para se aventurar nessas novas danças que movimentam o corpo, muito além do que na época se considerava aceitável ou decente.

O impacto do rock no Brasil na segunda metade dos anos 1950 pode ser percebido no comentário de Erasmo Carlos sobre como foi tocado por essa onda (MEDEIROS, 1984, p. 14-15):

Eu tinha catorze anos quando começou minha vida de rockmaníaco. Para mim, o rock foi a coisa mais importante do século. Acho que a juventude começou a se libertar por causa dele, a sentir que mandava no mundo. Quando ouvia o rock and roll me dava uma vontade danada de ficar nu e sair pulando. Depois, soube que isso acontecia a milhares de outros jovens. Até parece que o rock foi um negócio astral que aconteceu para mostrar um caminho e mudar tudo.

É então que surgem no mercado brasileiro da música - em pleno auge da Bossa Nova - os irmãos Tony e Cely Campelo, que se tornarão uma referência para o público jovem. Cantando versões em português de rock, eles vão marcar uma ruptura com a tradicional canção brasileira - de bolero, samba-canção e dramáticas canções de amor, e até em relação à recente Bossa Nova, sofisticada musicalmente, mas que nunca se dirigiu especialmente ao público jovem. Em pouco tempo, Cely Campelo se tornaria no maior sucesso da música brasileira e, maior novidade de todas, tendo como seu público quase que exclusivo, os jovens urbanos brasileiros. O primeiro grande sucesso de Cely Campelo foi a canção Estúpido Cupido ((Stupid Cupid Howard Greenfield / Neil Sedaka - Versão: Fred Jorge).

A ingenuidade da letra de Estúpido Cupido se repete nos sucessos seguintes de Cely Campelo: Biquíni de Bolinha Amarelinha (Itsy bitsy teenie weenie yellow polka dot bikini, de Lee Pockriss e Paul Vance - Versão: Hervé Cordovil), Banho de Lua (Bruno De Filippi/ Franco Migliacci - Versão: Fred Jorge), e Lacinhos Cor de Rosa (de Mickey Grant - Versão: Fred Jorge).

Todas elas versões de músicas estrangeiras, foram sucessos avassaladores e serviu como as fundações do rock no Brasil, uma construção que só seria erguida anos mais tarde. Mas o abandono da carreira por Celly para se casar em 1962, no auge do sucesso, mostrava que ela ainda não era a figura feminina que a história precisava para representar as novas conquistas das mulheres que marcariam os anos $1960 \mathrm{e}$ 1970 no Brasil e no mundo.

No eixo Rio-São Paulo - sedes das gravadoras brasileiras, das emissoras de TV e principais rádios produtores, empresários e descobridores de talentos começaram a procurar jovens para ocupar o trono vazio dos primeiros ídolos. É esse movimento, junto com a busca dos próprios artistas por um lugar na música brasileira, que vai favorecer o surgimento de toda uma geração de jovens talentosos, urbanos, abertos às novidades e conquistados pela onda do rock e pop internacional.

Entre 1962, ano da "abdicação" da rainha do rock brasileiro, Cely Campelo, e em 1964, os principais 
nomes que mais tarde viriam a compor a geração da Jovem Guarda davam seus primeiros passos profissionais e conquistavam seus primeiros sucessos nas rádios: Roberto Carlos, Wanderléa, Erasmo Carlos, Rosemary, Wanderley Cardoso, Jerry Adriani estavam nas paradas. Dezenas de jovens talentosos gravavam do rock ao pop, sempre valorizando as canções românticas, e em dois ou três anos praticamente eclipsaram os grandes artistas e as grandes divas da música brasileira. Foi o momento em que os pais - que decidiam o consumo e o sucesso - foram superados pelos filhos, que passaram a ditar as tendências do mercado da música. Essa revolução comportamental que começa nos anos 1950 do pós-guerra e se dissemina nos anos 1960 vai afetar o mundo e o sistema capitalista (HOBSBAWM, 1995).

Os meios de comunicação de massa tornam-se uma marca fundamental do sistema capitalista, objeto dos estudos hoje clássicos da Escola de Frankfurt, e o conceito de sociedade de massas é criado, nos anos 1950, por Theodor W. Adorno e Max Horkheimer, mas ajustado pelo próprio Adorno, para outro conceito, ainda mais crítico, de indústria cultural, por meio de uma série de pronunciamentos nas rádios, que mais tarde seria publicada em livro (ADORNO, 2002).

É o público jovem o mais atingido por essa onda capitalista, que vai proliferar não só por meio do cinema e da televisão, como principalmente da música, que se torna um elemento fundamental na expansão dessa indústria cultural que, mais do que apenas estimular o consumo de produtos, passa a influenciar as grandes modificações de comportamento das sociedades.

\section{A NOVIDADE TEM NOME: IÊ-lÊ-lÊ}

Inicialmente, a expressão usada para se referir a essa nova e impressionante safra de artistas jovens foi "iê-iê-iê", atribuído especialmente à música dançante que era uma espécie de rock brasileiro do início dos anos 1960. Dizia-se que Roberto Carlos, Erasmo Car- los, Wanderléa e toda a turma do que mais tarde seria chamado de Jovem Guarda faziam iê-iê-iê. Esse termo surgiu da música "She Loves You", em que os Beatles repetiam "yeah-yeah-yeah" no refrão. Essa expressão para nominar a musica jovem da época, entretanto, foi tão importada quanto as próprias músicas.

Ela começa a ser usada na França e, em seguida, em Portugal, conforme registrado na introdução do livro (CORTEZ APUD ALMEIDA, 2014, p. 13), sobre o ié-ié português (ALMEIDA, 2014), em que são catalogadas todas as bandas que representaram essa música jovem em Portugal, no período:

\begin{abstract}
Depois do rock'n'roll e do twist, e na ausência de um termo que caracterizasse a produção musical juvenil [...] ié-ié passou a ser o rótulo aplicado a todos os conjuntos que tocavam uma música assente no uso da guitarra elétrica, com um ritmo da bateria marcado e influência anglo-saxônica vincadas, sobretudo de origem inglesa ou, especificamente, tipo Beatles.
\end{abstract}

Esse termo, adotado por Portugal comoié-ié e no Brasil como iê-iê-iê, foi primeiro adotado na França, que recebia a influência do nascente pop inglês muito rapidamente, afinal, separados apenas pelo canal da Mancha, como lembra Cortez, a propósito da criação da expressão iê-iê-iê:

Termo francês criado pelo programa de rádio Salut les Copains, derivado dos “yeah!yeah!"das canções, o ié-ié chega a Portugal de forma descontextualizada e é explorado por uma imprensa mal informada. Se, no país de origem, se reportava sobretudo a jovens cantoras, ícones de sensualidade e alguma inocência - Françoise Hardy, Sylvie Vartan, Sheila - com os devidos rapazes a acompanhar - Antoine, Jacques Dutronc, Johnny Halliday - em Portugal, em anos de beatlemania, erroneamente recorreu-se à designação para englobar e descrever os novos conjuntos que surgiram sobretudo entre 1964 e 1967. (CORTEZ, 2014, p. 34).

No Brasil, apaixonado pela Bossa Nova, Roberto Carlos vai tentar o sucesso com músicas do gênero e nada vai acontecer. Seus dois primeiros discos são fracasso de vendas e ninguém conhece o artista. Finalmente, entrando na lógica do mercado, ele resolve 
gravar rock e estoura em todo o país, em 1962, com Splish Splash, seguindo a onda das versões em português do rock americano ou ingles (PUGLIALLI, 2006). Em seguida, ainda no mesmo ano, ele conquista novamente o primeiro lugar nas paradas com Parei na contra mão, que se torna o primeiro grande sucesso composto pela dupla Roberto Carlos/Erasmo Carlos. No final do ano ele lança um Long Play (LP) com as duas canções e, a partir daí, nada mais represa a onda rejuvenescedora que vai dominar o mercado da música no Brasil.

A partir daí, o iê-iê-iê, ou a música jovem brasileira vai evoluir, conquistando mais sucesso com o lançamento de dezenas de novos artistas e agora não apenas com versões de sucessos estrangeiros, mas também com canções originais - ainda que claramente influenciadas pelos ritmos estrangeiros - que passavam a falar cada vez mais com o jovem urbano brasileiro, estabelecendo uma cumplicidade com o público que garantiria a solidez das carreiras desses artistas. Erasmo Carlos, Wanderley Cardoso, Jerry Adriani, Renato e Seus Blue Caps, Eduardo Araújo, e outros artistas da Jovem Guarda já eram sucesso antes da estreia do programa que deu nome ao movimento.

São centenas de músicas que marcaram época e que, em termos de gênero musical, mostraram uma diversidade enorme: rock influenciado pelo rock americano; pop influenciado pelos Beatles - que, antropofagicamente, inspiraram o iê-iê-iê brasileiro - a música romântica "moderna", influenciada pelas canções italianas e francesas; o country; o samba; o samba-rock; eles experimentavam de tudo. Os artistas tentavam a fórmula do sucesso total: emplacar nas rádios tanto música dançante quanto canções românticas.

\section{IÊ-IÊ-IÊ PASSA DE IMPORTADO A PRODUTO NACIONAL}

A estratégia de gravar versões em português de sucessos estrangeiros foi usada por todos os grandes nomes da Jovem Guarda: Roberto Carlos e Erasmo fi- zeram sucesso com versões de músicas americanas. Jerry Adriani chegou a gravar um LP inteiro cantando em italiano. Mas todos eles seguiram suas carreiras e ampliaram seu sucesso, cantando músicas compostas em português, por eles mesmos e dezenas de outros compositores brasileiros, que geraram um acervo de sucessos sem precedentes.

As versões em português, de canções estrangeiras, principalmente do nascente pop inglês e do rock americano, foi um dos principais motivos para os artistas dessa nova onda jovem, que começavam a conquistar enorme sucesso no Brasil, serem desprezados pela crítica e pelos intelectuais. Entretanto, essa estratégia mercadológica acabou resultando num fato cultural e econômico que iria marcar positivamente a crescente importância do mercado brasileiro da música: o Brasil entre os anos 1960 e 1990 se tornou um dos raros países do mundo em que o mercado da música era dominado majoritariamente pela música nacional, cantada em português.

O próprio conteúdo das letras, que expressava 0 universo de certa juventude urbana que crescia rapidamente no Brasil, em geral, não tinha relação direta com as letras originais das canções estrangeiras. Por exemplo, o primeiro sucesso de Roberto Carlos, Splish Splash (Bobby Darin - Jean Murray) foi gravado numa versão em português, escrita por Erasmo Carlos que não sabia inglês e que usou apenas a sonoridade original para criar a letra em português.

A força dos artistas jovens brasileiros é tamanha que, enquanto os Beatles estouravam no mundo inteiro e continuavam pouco conhecidos no Brasil, Carlos Imperial, uma espécie de produtor, aventureiro e um dos maiores descobridores de talentos da história da música brasileira, (MONTEIRO, 2015, p. 137/139), apresenta ao conjunto Renato e Seus Blue Caps um compacto com a canção / Should Have Known Better (John Lennon / Paul McCartney), dos Beatles, para eles cantarem ao vivo no dia seguinte, no programa da Rádio Carioca Os Brotos Comandam. 
Como eles tiveram muita dificuldade de cantar a canção em inglês, Renato Barros vez uma versão em português, chamada Menina Linda e, assim, o conjunto cantou ao vivo para o auditório da rádio, no dia seguinte. 0 sucesso foi tão grande que a música entrou no primeiro LP do grupo, Viva a Juventude. Em pouco tempo, a faixa era um dos maiores sucessos do ano no Brasil, tocando nas rádios de todo o país, sucesso nunca superado, por ironia, pelas canções originais dos Beatles, quando mais tarde passaram a tocar nas rádios brasileiras.

\section{A JUVENTUDE SURGE COMO SEGMENTO SOCIAL E DE MERCADO}

O fenômeno da música jovem vai provocar no Brasil o mesmo que acontecia com o rock americano e o pop inglês: fãs desesperadas, aos gritos, compareciam e disputavam os lugares nos auditórios das rádios - que na época gravavam programas musicais com apresentações ao vivo dos artistas (AGUILLAR, 2005). Muito mais do que o fenômeno de popularidade das cantoras do rádio, como Emilinha Borba, Marlene e Angela Maria, as fãs dos artistas do iê-iê-iê demonstravam um entusiasmo que era visivelmente sexual. 0 artista preferido era também a fantasia de amor e sexo longe dos casamentos programados e "chatos" desejados pelos pais.

Essa tendência de "revolução da juventude", a partir das mudanças de costumes, foi uma onda que se propagou no mundo ocidental. 0 sucesso dos artistas do iê-iê-iêtem impacto em todas as mídias brasileiras. Pela primeira vez, as revistas femininas, recordistas de vendas na época, substituem os manequins e artistas de fotonovelas em suas capas pelos artistas jovens da música brasileira. São os primórdios das atuais revistas de celebridades. Notícias do cotidiano da vida desses artistas, fofocas picantes sobre suas aventuras amorosas e sobre a competição entre os pares se tornam foco obrigatório das revistas, com grande repercussão na vendagem.
As editoras passam a ter o público jovem como alvo para dinamizar o mercado editorial. A TV no Brasil, ainda restrita às grandes capitais, e com pouquíssima penetração no interior, começa a buscar - por meio dos anunciantes e da crescente indústria brasileira novos segmentos de público e é nesse momento que "descobre" os jovens como consumidores.

Os artistas jovens formam a primeira geração da música brasileira que usa a TV - além do rádio, já consagrado - como meio de divulgação das músicas. Para dar mais impulso a esse movimento, a inovação do videotape, adotada pela TV brasileira em 1965, vai permitir que os programas ao vivo, restritos aos mercados locais, comecem a ser exibidos em outras praças. São os primeiros passos do que mais tarde se tornariam as grandes redes de TV, atingindo todos os Estados brasileiros nos anos 1970.

\section{UM PROGRAMA DE TV REVOLUCIONA O MERCA- DO DA MÚSICA NO BRASIL DA DITADURA}

O crescente sucesso dessa nova geração de artistas jovens influenciados pelo rock e pop inglês e americano da época atingiu sua consagração com o lançamento do programa Jovem Guarda na TV Record, em 1965. O programa era comandado por Roberto Carlos e seus amigos Erasmo Carlos e Wanderléa. A ideia de convocar os dois para dividir a apresentação do programa partiu de Roberto (CARLOS, 2009). A lista de músicos que se apresentavam no programa era extensa: Golden Boys, The Fevers, Renato e seus Blue Caps, Jerry Adriani, Wanderley Cardoso, Martinha, Vanusa, Ronnie Von, Eduardo Araújo, Os Incríveis, Rosemary, Sérgio Reis, Silvinha, Ronnie Cord, Waldirene, Leno e Lilian, Os Vips, Nilton César e Trio Esperança, entre outros.

A importância do programa foi decisiva para difundir uma estética daquele movimento, com roupas coloridas e extravagantes, um figurino que remete ao movimento hippie, à pop art e ao psicodelismo da última parte dos anos 1960. Tendo a TV e as revistas como meios de pro- 
pagação da imagem, os artistas começam a influenciar o modo de vestir, o comportamento, as gírias e os hábitos da juventude brasileira. Quando o programa Jovem Guarda estreou, em 22 de agosto de 1965, a música jovem brasileira, chamada até então de iê-iê-iê, já tornara famosos os nomes que se vinculariam ao programa, além dos três apresentadores, Roberto e Erasmo Carlos e Wanderléa, sem dúvida os mais bem-sucedidos dentre todo o enorme grupo de artistas.

O Brasil completava, então, uma década de política desenvolvimentista, inaugurada pelo governo Juscelino Kubitschek, desde sua posse em 1955. Era a primeira fase da ditadura militar que iria recrudescer numa onda crescente de autoritarismo até o fechamento do Congresso Nacional com o Al-5, em 1969. O Brasil se encontrava uma fase de desenvolvimento econômico que resultaria nos recordes de crescimento do país nos anos 1970, associados a uma estratégia de metropolização. Em poucos anos o Brasil foi-se transformando de forma rápida e consistente num país urbano, cada vez mais diferente do país rural que existira até a primeira metade do século XX.

Essa concentração, num curto período de tempo, da população brasileira nas cidades, iria ter enorme impacto nas mudanças de comportamento social. Era um terreno fértil para a emergência de uma juventude que adotava novos valores e se distinguia, cada vez mais, das gerações que the antecederam. 0 rock no mundo ocidental e a Jovem Guarda no Brasil são o símbolo dessa nova onda jovem que vai transformar as sociedades capitalistas ocidentais sem possibilidade de retorno.

O surgimento da Jovem Guarda, nos anos 1960, acontece quando começa a se disseminar o conceito de Economia da Cultura (BENHAMOU, 1996), que vai evoluir nas próximas décadas para os conceitos de indústrias criativas e economia criativa, que tentam explicar a importância da cultura na economia do século XXI (MIGUEZ, 2009). É um momento em que a disseminação dos meios de comunicação de massa, principalmente com a popularização da TV nas socie- dades ocidentais, vai trazer a indústria cultural para o centro da economia mundial. A partir desse grande impacto do surgimento do segmento de consumo da juventude, a economia capitalista mundial vai iniciar, a partir das décadas seguintes, um novo processo de inovação tecnológica, associada à comunicação e à informação, que transformará as bases do capitalismo e do comportamento no mundo até os dias atuais.

A Jovem Guarda vai representar, no Brasil, todo esse processo de inovação tecnológica e impacto na economia. Ela explora o mercado da música como nunca antes: além dos discos, shows e programas de rádio, é a primeira geração de artistas que vai atuar e usar a TV como meio de promoção e comercialização da música. Além disso, vão impactar em vários setores da economia: a moda, o licenciamento, a publicidade, o merchandising, o cinema, as revistas. É com a Jovem Guarda que a música, definitivamente, se torna, no Brasil, um produto de consumo de massa em suas múltiplas possibilidades mercadológica.

É, na realidade, uma antecipação do que nos anos 2000 vai se conceituar como indústrias criativas (BENDASSOLLI ET AL., 2009), que são constituídas a partir de algumas características: a criatividade como elemento central; a produção de objetos culturais; o valor econômico da propriedade intelectual; o pressuposto de convergência entre artes, negócios e tecnologia. Hoje, quando um dos setores da economia que mais veiculam publicidade, a telefonia, compete tenazmente pela conquista do público jovem, podemos constatar a importância não só estratégica, mas de impacto efetivo desse consumo da juventude no capitalismo internacional contemporâneo.

\section{A JOVEM GUARDA VIRA MERCADORIA: MODA, ACESSÓRIOS, GADGETS}

Wanderléa, Roberto Carlos e Erasmo Carlos à frente, tudo que os artistas usam vira moda. Essa influência consolida uma tendência iniciada timidamente no 
final dos anos 1950: os jovens começam a se vestir de forma totalmente diferente dos pais. 0 segmento jovem no mercado de consumo da moda se estabelece como novo desafio da indústria. No livro de Maira Zimmermann sobre a relação entre a Jovem Guarda e a moda (ZIMMERMANN, 2013, p. 116-118), a autora faz uma análise detalhada do figurino transgressor dos artistas, a partir de uma foto que se tornou icônica, representação síntese que simbolizou o movimento.

Foto essa produzida e publicada pela editora Abril e encartada como poster em seis partes, distribuídas em três edições da Revista Contigo e outras três da revista Noturno. Essa imagem, que expressava o figurino que os artistas usavam em seus shows e programas de TV, e que permanence até hoje como representação da Jovem Guarda, foi dissecada pelo olhar especializado da autora, primeiro avaliando os rapazes:

Na Jovem Guarda, são visíveis a mescla de estilos e a visualidade exuberante que o grupo apresentava já no auge do programa (...) os homens adotam cores, acessórios e adereços antes restritos apenas ao universo feminino. [...] Com cores e vivacidade, Eduardo Araújo começa a apresentar-se nos programas com camisa de babados e os cabelos bastante compridos; Wanderley Cardoso, com terno de seis botões rosa-choque; Roerto Carlos com camisa rosa-choque, cal;ca ajustada na canela, anéis, pulseira, corrente dourada, cinto estampado, além de apresentar, também, os cabelos bem compridos. Erasmo Carlos, assim como Roberto, com casaco com referências militares (uma provável influência da transfromação estética dos Beatles, em 1967, com o lançamento do LP Sgt. Pepper's), camisa verde, óciulos coloridos, além de corrente dourada e anéis. (ZIMMERMANN, 2013, p. 116-118).

Em seguida, ela se detém nas características das mulheres ali presentes como força natural do movimento:

Wanderléa e Martinha representam estilos distintos. Apresentam em comum o cabelo bastante longo e alisado e a maquiagem inspirada em Twiggy e Eddie Sedgwick, musa de Andy Warhol, olhos redondos e carregados de maquiagem, com cílio postiço, muito rímel e delineador. A pele, porém, em contraste, era bastante pálida, enfatizando a "jovialidade natural". Wanderléa, em uma atitude desafiadora, até então restrita aos homens, veste camisa vermelha com mangas bufantes e colete branco, calça pantalona preta de cintura alta, óculos coloridos e correntes, com sapato de salto de verniz vermelho, aproximando-se do estilo psicodélico da Swinging London. Martinha exibe o baby style: veste microvestido vermelho, com bolinhas e punhos brancos, laço na cabeça e sapatos boneca brancos, influência do estilo mod feminine. (ZIMMERMANN, 2013, p. 116-118).

Os ícones femininos surgidos nessa geração de artistas eram diversos e representavam as múltiplas faces do Brasil urbano em construção: cariocas, paulistas, mineiras, suburbanas ou de classe média baixa, as cantoras da Jovem Guarda vão popularizar nos quatro cantos do país uma espécie de modo jovem e moderno de viver, ainda que seu discurso fosse raramente revolucionário ou contestador. Wanderléa, a mais influente nesse quesito, usava minissaias muito mais curtas do que a lançada pela estilista inglesa Mary Quant e tornada ícone mundial pela modelo Twiggy, no auge do movimento swinging London, dos anos 1960.

Wanderléa vai se tornar o mais importante ícone feminino da música jovem na época. Mas além dela, outras artistas como Rosemary, Waldirene, Martinha, Elisabeth e Vanusa são a representação da modernidade que o próprio país está esboçando para si e, apesar da ditadura se instala no Brasil, a partir de 1964, as mudanças comportamentais da juventude não vão mais voltar atrás.

Os artistas da Jovem Guarda se tornaram licenciadores de produtos os mais diversos: além de roupas e adereços, chaveiros, pulseiras, álbum de figurinhas etc. Aos poucos, vai tomando forma uma mais ampla e inovadora relação da música com o mercado, extrapolando os formatos tradicionais: discos, shows e apresentações em rádio e TV. Essas ações eram inovadoras no Brasil, onde não havia, ainda, uma lógica comercial estabelecida e consagrada para o que hoje chamamos de licenciamento de produtos. Wanderléa declarou numa entrevista: "Fui boneca da Estrela e considerei isso, na época, uma homenagem. Não recebi royalties pelo uso da minha imagem" (Revista 
TPM, 2009). Ou seja, apesar de terem ganhado muito dinheiro na época, os artistas certamente receberiam muito mais pela lógica do mercado atual.

\section{A LONGEVIDADE NO MERCADOE NO IMAGINÁRIO DOS FÃS}

O ano de 1968 vai ser um divisor de águas no destino da turma da Jovem Guarda. O programa da TV Record se encerra em junho daquele ano. Wanderléa e Erasmo comandam novo programa, tentando prolongar a onda de sucesso. Mas o grande golpe que abala definitivamente aquela já longa permanência no auge do sucesso é o casamento de Roberto Carlos, em maio de 1968, pouco antes de acabar o programa. 0 casamento do maior ídolo da Jovem Guarda foi um balde de água fria no entusiasmo juvenil e hormonal das fãs. Ainda mais, porque ele se casou com uma mulher mais velha, que já tinha uma filha e era desquitada na época, um escândalo para um país católico e conservador (FRÓES, 2000).

O programa da TV Record foi ao ar de agosto de 1965 a junho de 1968. Com o seu final, o movimento começou a perder o fôlego. Mas, o grupo de artistas e as músicas por eles gravadas continuaram por muito mais tempo como peças importantes do mercado da música brasileira. Muitos chegaram ao primeiro lugar nas paradas de sucesso até meados dos anos 1970, com o mesmo tipo de música da Jovem Guarda. Foi o período da chamada "última safra" do movimento: Vanusa, Antonio Marcos, Paulo Sérgio, Adriana, Elizabeth. Em meados dos anos 1970, esses artistas, assim como Jerry Adriani, seguiam fazendo sucesso, mas sua estética aos poucos foi saindo da classificação de música jovem e passou a ser vista pela imprensa como música brega ao lado de legítimos representantes do segmento, como Odair José, Diana, Fernando Mendes e Reginaldo Rossi.

O primeiro disco lançado por Roberto Carlos, 0 Inimitável, depois do fim do programa Jovem Guarda, trazia duas prioridades: uma, expressa no título, era deixar claro que ele não entregaria o posto de rei da música popular. Na ocasião, havia surgido, com sucesso espetacular, Paulo Sérgio, com a música Última Canção, que estourou nas paradas em todo o Brasil. Era a primeira vez que outro artista, de fato, parecia abalar o lugar de Roberto Carlos no mercado (ARAÚJO, 2009). A outra prioridade do rei era mostrar a beleza da sua voz e sua versatilidade como intérprete, em canções mais maduras e elaboradas. Elas exploravam novas possibilidades com o soul e um rock mais profundo (SANCHES, 2004), abandonando uma das características mais marcantes da Jovem Guarda, que era certa inocência e leveza.

Além das tentativas de Wanderléa de se descolar da imagem da Jovem Guarda, experimentando outras sonoridades e se juntando com produtores e músicos de vanguarda, também Erasmo Carlos seguiu tentando na carreira solo investir mais na sua veia roqueira, caminho totalmente abandonado pelo seu eterno parceiro Roberto Carlos. Apesar de eventuais sucessos e do reconhecimento obtido nas décadas seguintes, praticamente nenhum dos artistas, à exceção de Roberto Carlos, conseguiu se dissociar da Jovem Guarda.

0 que pode eventualmente ter sido motivo de grande insatisfação artística e de frustração na busca do sucesso - ficar preso ao repertório daquela época - acabou sendo a razão de uma longevidade sem precedentes da música brasileira.

Os artistas da Jovem Guarda chegam à celebração dos 50 anos de surgimento do programa, em 2015, ativos e continuando a encantar em shows por todo o Brasil, além de ter suas músicas regravadas, exaustivamente, nas últimas décadas, tantos pelos artistas das novas gerações, como por nomes consagrados da música brasileira. Wanderléa, Erasmo Carlos, Eduardo Araújo, Jerry Adriani, Wanderley Cardoso, Martinha, todos continuam na ativa e atraindo para seus shows a legião de fãs que conquistaram meio século atrás. Junto com seus filhos e netos, e até bisnetos, os fãs da Jovem Guarda não desistem. 


\section{REFERÊNCIAS}

ADORNO, T. W. Indústria cultural e sociedade. São Paulo: Paz \& Terra, 2002. 120p.

AGUILLAR, Antonio. Histórias da Jovem Guarda. São Paulo: Globo, 2005. 220p.

ALMEIDA, Luis Pinheiro de. Biografia do lé-ié. Sintra: Documenta, 2014. 328p.

ARAUJO, Paulo Cesar de. Roberto Carlos em

Detalhes. São Paulo: Planeta, 2006. 504p.

BENDASSOLLI, Pedro F. et al. Compreendendo as indústrias criativas. In: WOOD JR. et al. (Coord.). Indústrias Criativas no Brasil - Cinema, TV, Teatro, Música, Artesanato, Software. São Paulo: Atlas, 2009. 218p.

BENHAMOU, Françoise. L'Economie de la Culture. Paris: La Decouverte, 1996 (ed. 2011).120p.

CARLOS, Erasmo. Minha fama de mau. Rio de Janeiro: Objetiva, 2009. 360p.

CORTEZ, Afonso. Introdução. In: ALMEIDA, Luis Pinheiro de. Biografia do lé-ié. Sintra: Documenta, 2014. 328p.

FRÓES, Marcelo. Jovem Guarda - em ritmo de aventura. São Paulo: 34, 2000. 288p.

HOBSBAWM, Eric. A Era dos extremos - o breve século XX - 1914-1991. São Paulo: Companhia das Letras, 1995. 600p.
LEMOS, Nina. Sem perder a ternura: Wanderléa, a princesa da jovem guarda, finalmente resolve falar. TPM Revista. 13.3.2009. Disponível em: <http://revistatpm.uol.com.br/revista/81/semperder-a-ternura/page-2.html>. Acesso em:10 dez. 2014.

MIGUEZ, Paulo. Os estudos em economia da cultura e indústrias criativas. In: WOOD JR. et al. (Coord.). Indústrias criativas no Brasil - cinema, TV, teatro, música, artesanato, software. São Paulo: Atlas, 2009. 218p.

MONTEIRO, Denilson. Dez, nota dez! Eu sou Carlos Imperial. São Paulo: Planeta, 2015. 408p.

PAGLIA, Camille. Personas sexuais. São Paulo: Companhia das Letras, 1992. 656p.

PUGIALLI, Ricardo. Almanaque da jovem guarda - uma década cheia de brasa, mora? São Paulo: Ediouro, 2006. 336p.

SANCHES, Pedro Alexandre. Como dois e dois são cinco - Roberto Carlos (\& Erasmo \& Wanderléa). São Paulo: Boitempo, 2004. 416p.

SAVAGE, Jon. A criação da juventude - como o conceito de teenage revolucionou o século 20. Rio de Janeiro: Rocco, 2009. 558p.

ZIMMERMANN, Maíra. Jovem Guarda: moda, música e juventude. São Paulo: Estação das Letras, FAPESP, 2013. 212p. 
Recebido em: 11 de Agosto de 2015 Avaliado em: 31 de Agosto de 2015 Aceito em: 31 de Agosto de 2015

\begin{abstract}
1. Doutor em Sociologia das Organizacões - Université de Paris VII - Dennis Diderot (2000). Especialização em Gestão Pública (1991) e Mestrado em Administração pela Universidade Federal da Bahia (1993). Graduação em Comunicação (1982). Professor Adjunto do Centro de Cultura, Linguagens e Tecnologias Aplicadas (CECULT) da Universidade Federal do Recôncavo da Bahia (UFRB). Pesquisador nas áreas de Economia da Cultura, Gestão Cultural, Identidade e Cultura, Cultura Organizacional, Diversidade Cultural e Gestão Pública e Social. Livros publicados: Olodum - De Bloco Afro a Holding Cultural (1994), Diversidade Sexual e Trabalho (2012). E-mail: mdantas50@gmail.com
\end{abstract}

